\title{
Ocean circulation in the North Pacific during the last glacial termination
}

\author{
Yusuke Okazaki ${ }^{1,2}$, A. Timmermann ${ }^{3}$, L. Menviel ${ }^{4}$, M.O. Сhikamoto ${ }^{3}$, N. Harada ${ }^{2}$ and A. Abe-Ouchi ${ }^{2,5}$ \\ 'Department of Earth and Planetary Sciences, Kyushu University, Fukuoka, Japan; yokazaki@geo.kyushu-u.ac.jp \\ 2Research Institute for Global Change, Japan Agency for Marine-Earth Science and Technology, Yokosuka, Japan; ${ }^{3}$ nternational Pacific Research \\ Center, School of Ocean and Earth Science and Technology, University of Hawaii, Honolulu, USA; ${ }^{4}$ Climate Change Research Centre, University of \\ New South Wales, Sydney, Australia; ${ }^{5}$ Atmosphere and Ocean Research Institute, University of Tokyo, Kashiwa, Japan
}

Sedimentary and modeling evidence presume a major deglacial switch between the sites of deepwater formation in the North Atlantic and North Pacific. These results suggest that the North Pacific may have played a more prominent role in organizing the global ocean circulation and shifting climate regimes than previously thought.

T he North Pacific is considered a terminal region of the "Ocean's Conveyer belt circulation". Abyssal waters from the south flow into the North Pacific, upwell to mid-depth, mix with surrounding waters, and return south (Schmitz 1996). In this configuration and as a result of mixing, the present North Pacific is characterized by high concentrations of surface nutrients, thus promoting high biological productivity. Today, no deep water forms in the North Pacific in response to surface buoyancy fluxes because the surface water of the North Pacific is not saline and dense enough to trigger deep convection and downwelling (Warren 1983). However, in certain areas, such as the Okhotsk Sea, surface conditions are still favorable to form North Pacific Intermediate Water (NPIW) to depths of about 300 to $800 \mathrm{~m}$ (Talley 1993).

\section{Last Glacial Maximum}

The glacial Pacific Ocean had two water masses: well-ventilated and nutrientdepleted glacial NPIW above $\sim 2000$ $\mathrm{m}$ and less-ventilated and nutrientenriched deep water below $\sim 2000 \mathrm{~m}$ (Keigwin 1998; Matsumoto et al. 2002). Compared to today, the NPIW volume under glacial conditions was significantly higher extending down to about 2000 m. Microfossil (Ohkushi et al. 2003) and neodymium isotope data (Horikawa et al. 2010) suggest that the glacial NPIW possibly originated from the Bering Sea. This "stratified" water mass structure of the glacial North Pacific prevented upwelling of nutrient-rich deep waters. Thus, biological productivity in the glacial North Pacific was relatively low (Narita et al. 2002; Jaccard et al. 2005; Galbraith et al. 2007; Brunelle et al. 2010).

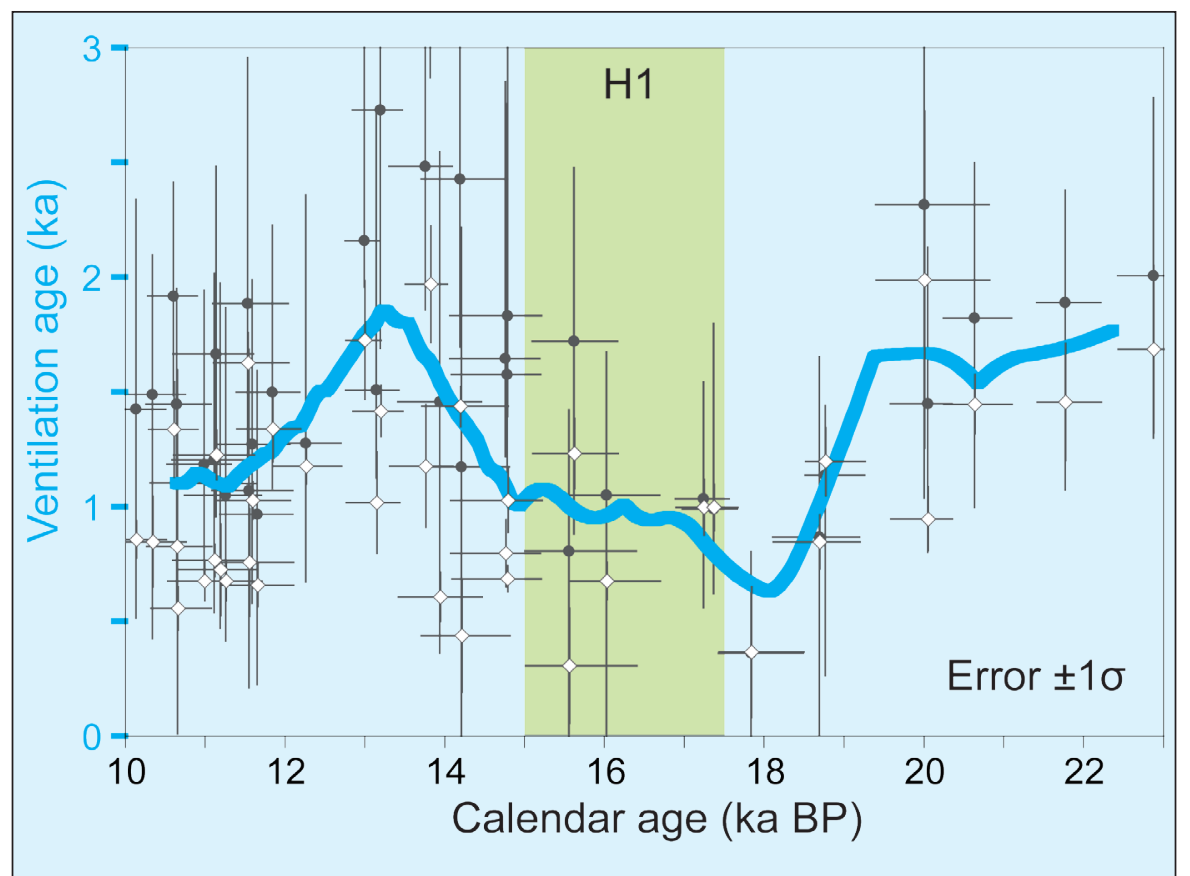

Figure 1: Ventilation age changes based on published radiocarbon data in the western North Pacific between 900 and $2800 \mathrm{~m}$ water depths (Okazaki et al. 2010). Reconstructed ventilation change based on the ${ }^{14} \mathrm{C}$ age offset between co-existing benthic (BF) and planktic foraminifers (PF; open diamonds), projection ages (considering atmospheric ${ }^{14}$ C change; gray circles), and smoothed spline interpolation of averaged BF-PF age offsets and projection ages (blue line). H1: Heinrich event 1.

\section{Last Glacial Termination}

Major reorganization of water-mass structure in the North Pacific occurred during the last glacial termination, when a stratified glacial mode transformed to an upwelling interglacial mode. During the early period of the termination between 17.5 and $15 \mathrm{ka} \mathrm{BP}$, the Meridional Overturning Circulation (MOC) in the Atlantic substantially weakened (McManus et al. 2004) due to freshwater forcing by melting icebergs in the North Atlantic (Heinrich event $1 ; \mathrm{H} 1)$. A compilation of sedimentary radiocarbon ventilation records in the North Pacific and freshwater perturbation experiment mimicking a Heinrich event performed with the earth system model of intermediate complexity, LOVECLIM, suggest that deep water formation in the North Pacific extended to a depth of 2500 to 3000 m during H1 (Fig. 1 and 2; Okazaki et al. 2010; Menviel et al. 2011). The establishment of the Pacific MOC during times of Atlantic MOC weakening could have played an important global role in regulating poleward oceanic heat transport during $\mathrm{H} 1$.

During the Bølling-Allerød period (15-13.0 ka BP) and after the Younger Dryas (13-11.5 ka BP), the ocean circulation in the North Pacific resumed to an interglacial mode without deep-water formation, similar to the modern condition. At the beginning of the Bølling-Allerød, productivity in the subarctic Pacific rose rapidly (Crusius et al. 2004; Galbraith et al. 2007; Brunelle et al. 2010) in association with enhanced upwelling and breakdown of the glacial stratification.

The Atlantic MOC was weakened during the Younger Dryas event, but not as much as during $\mathrm{H} 1$ (McManus et al. 2004). Oceanic ventilation in the North Pacific during the Younger Dryas appeared to be stronger than that of the Bølling-Allerød possibly responding to the MOC weakening in the Atlantic. However, it is unclear 
whether an MOC was established or not in the Pacific during the Younger Dryas.

\section{Role of the Bering Strait}

Modeling studies demonstrate that a closed Bering Strait (sill depth $50 \mathrm{~m}$ ) is required for the build-up and maintenance of higher surface salinity in the North Pacific during Heinrich events (Saenko et al. 2004; Hu et al. 2007; Okazaki et al. 2010), which is a precondition for establishing MOC in the Pacific. The role of the final opening of the Bering Strait between 11 and $12 \mathrm{ka}$ BP (Keigwin et al. 2006) in the transition from the glacial to the modern NPIW regime is still not well understood.

\section{Perspectives}

Different thrusts have to be pursued to further elucidate the effects of North Pacific Ocean circulation changes on global climate change.

\section{Model intercomparison}

The establishment and extent of a Pacific MOC following an Atlantic MOC weakening are model-dependent (Chikamoto et al. 2012; Hu et al. 2012). Further model intercomparison studies should be performed to test the robustness of the proposed mechanism for the Pacific MOC set up as well as its extent in the North Pacific.

\section{Error reduction for reconstructed ventilation records}

As shown in Fig. 1, reconstructed ventilation data still have substantial errors. This is mainly caused by large uncertainties of

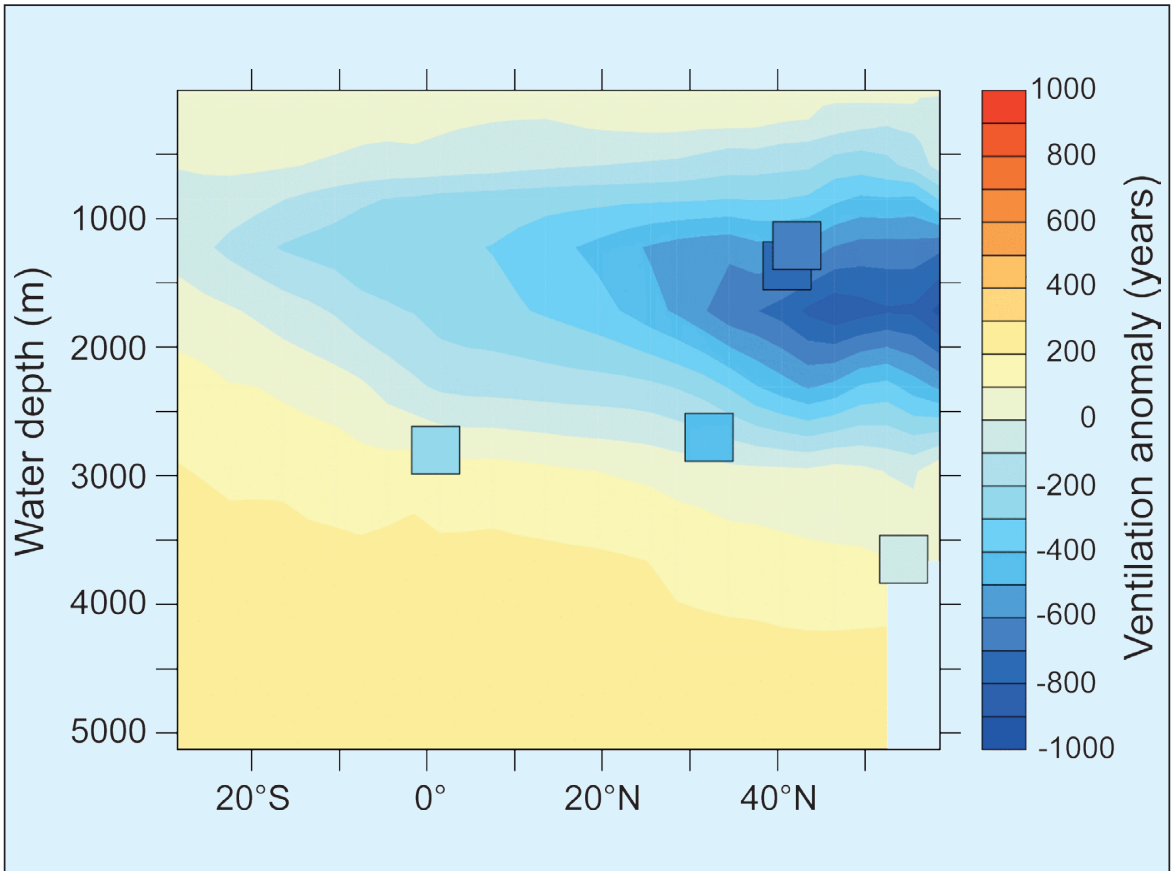

Figure 2: Zonally averaged simulated radiocarbon age anomalies in the North Pacific between a collapsed Atlantic MOC state and the preindustrial control simulation. Squares indicate projection age anomalies for the deglacial H1 period reconstructed from western North Pacific sediment cores (Okazaki et al. 2010).

the marine reservoir effect in the conversion from radiocarbon age to calendar age. In order to constrain the regional marine reservoir effect, precise age dating for the targeted sample is fundamental. High-resolution magnetostratigraphy and tephra chronology are potential tools for evaluating past regional marine reservoir ages.

\section{Reconstruction of the Bering Strait gateway history}

The Bering Strait opened and closed numerous times during the last glacial cycle (e.g. Brigham-Grette 2001). However, the detailed history is not reconstructed yet, but would provide new insights on the impact of this gateway on past global ocean circulation and climate change.

\section{Selected references}

Full reference list online under:

http://www.pages-igbp.org/products/newsletters/ref2012_2.pdf

Chikamoto M0 et al. (2012) Deep-Sea Research II 61-64: 114-126

Matsumoto K, Oba T, Lynch-Stieglitz J, Yamamoto H (2002) Quaternary Science Reviews 21: 1693-1704

Menviel L, Timmermann A, Timm OE, Mouchet A. (2011) Quaternary Science Reviews 30: 1155-1172

Okazaki Y et al. (2010) Science 329: 200-204

Saenko OA, Schmittner A, Weaver AJ (2004) Journal of Climate 17: 2033 2038

\section{Planning the next career step? Looking for new challenges? Searching for that perfect candidate?}

\section{Try the free PAGES Jobs Database}

Key features:

\section{Collates paleoscience-relevant job postings} from various listservs.

2. Allows you to post jobs directly through an online form.

\section{Features PhD studentships and non-scientific positions as well.}

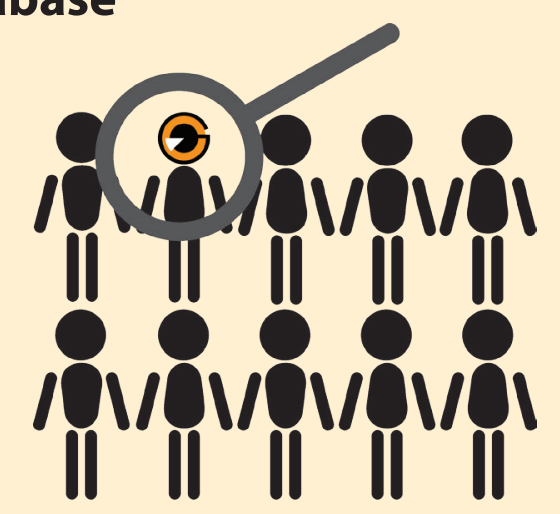

www.pages-igbp.org/my-pages/intro 